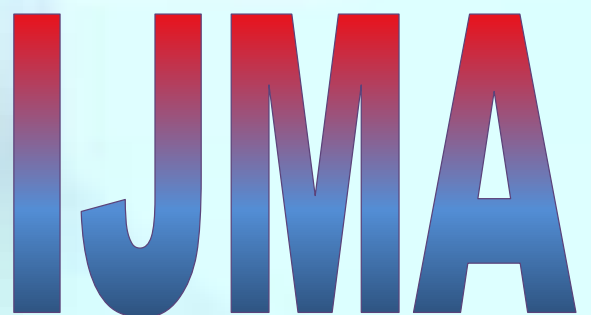

INTERNATIONAL

Journal of MEdical

\section{ARTS}

Volume 3, Issue 1 (Winter 2021)

http://ijma.journals.ekb.eg/

Print ISSN: 2636-4174

Online ISSN: 2682-3780

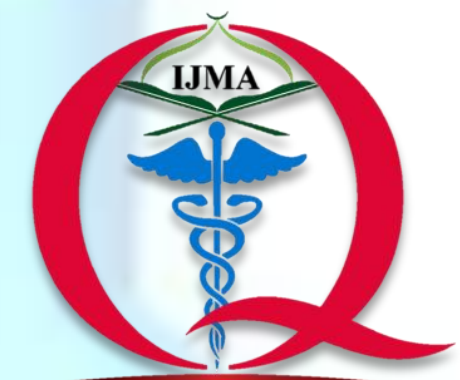

International Jounnal of Medical Arts

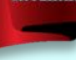





Available online at Journal Website
https://ijma.journals.ekb.eg/
Main subject [Orthopedic Surgery]

Original article

\title{
Use of Liquid Nitrogen as A local Adjuvant to Decrease Recurrence after Extended Curettage, and Reconstruction by Autogenous Bone Graft for Treatment of Aneurysmal bone Cyst: Our Updated Experience \\ Mohamed Abdel Rahman Mostafa[1]; Osman Abdellah Mohamed[2]
}

\author{
Department of Orthopedic Surgery, Faculty of Medicine, Ain Shams University, Cairo, Egypt ${ }^{[1]}$ \\ Department of Orthopedic Surgery, Damietta Faculty of Medicine, Al-Azhar University[2] \\ Corresponding author: Osman Abdellah Mohamed \\ Email: docosman@domazhermedicine.edu.eg \\ Received at: August 15, 2020; Revised at: October 25, 2020; Accepted at: October 26, 2020
}

DOI: 10.21608/ijma.2020.43006.1171

\section{ABSTRACT}

Background: Aneurysmal bone cyst $[A B C]$ can be managed by curettage and different bone grafts. However, the recurrence rate is high, and different adjuvants had been proposed to reduce recurrence. The use of liquid nitrogen could be used as an adjuvant.

Aim of the work: To present our experience with liquid nitrogen use as an adjuvant in ABC's management.

Patients and Methods: Twenty-five patients with $A B C$ had been evaluated. All were treated by extended curettage followed by liquid nitrogen for two cycles and reconstruction of the cavity by a bone graft. Radiological and functional outcomes had been documented, and any complications had been registered.

Results: Femur was the most common site for $A B C$. The graft was obtained from iliac crest for all patients, mainly corticocancellous [68.0\%]. The ABC grade was grade 2 among [80.0\%] and grade 3 among [20.0\%]. Graft union achieved in all patients in an average of $6.52 \pm 2.27$ months. The mean follow-up duration was [44.52 \pm 16.81 months; range 24- 72 months], and all patients were alive and completely free from the disease. The functional score ranged from $70 \%$ to $94 \%$, [average of $85.12 \pm 7.32 \%$ ]. Recurrence rate $[8.0 \%]$ and wound infection had been recorded in another two patients [treated conservatively and completely resolved within days].

Conclusion: Extended curettage of $\mathrm{ABC}$ with adjuvant cryotherapy had good results with a lower recurrence rate. The additional use of a bone graft allowed for consolidation in all cases with a short time for cyst healing.

Keywords: Recurrence; Aneurysmal Bone Cyst; Extended Curettage; Cryosurgery; Bone Grafting.

This is an open-access article registered under the Creative Commons, ShareAlike 4.0 International license [CC BY-SA 4.0] [https://creativecommons.org/licenses/by-sa/4.0/legalcode.

\footnotetext{
Please cite this article: Mohamed OA, Mostafa MA. Use of Liquid Nitrogen as A local Adjuvant to Decrease Recurrence after Extended Curettage, and Reconstruction by Autogenous Bone Graft for Treatment of Aneurysmal bone Cyst: Our Updated Experience IJMA 2021; 3[1]: 1007-1015. DOI: 10.21608/ijma.2020.43006.1171

${ }^{*}$ Main subject and any subcategories have been classified according to the research topic.
} 


\section{INTRODUCTION}

Aneurismal bone cyst $[A B C]$ of bone is a benign intraosseous [rarely arising from soft tissues] tumor-like lesion, first described in the 1940s. Irrespective of its benign nature, ABC could grow fast with the destruction of nearby bony structures. It could recur and typically affect long bone metaphysis and vertebral column[1].

$A B C$ is characterized as an aggressive, osteolytic and expansile, cystic lesion [blood-filled spaces divided by connective-tissue septa], representing $2.5 \%$ and $15.0 \%$ of all primary bone and spine tumors, respectively. It is either primary [70.0\%; mostly affecting second decades and $85.0 \%$ presented before the age of 20] or secondary [30\%] to other bone tumors. ABC had a female sex predilection with a female to male ratio of $2: 1$; malignant transformation is rare, and the recurrence rate is variable [5-24\%][2-5].

The mechanisms responsible for $A B C$ development remains unclear. Many theories had been proposed; $A B C$ could be developed as a reaction to vascular malformation due to trauma, and genetic factors are suggested to play a role[6].

Once the diagnosis is confirmed, surgical treatment is the standard choice to prevent pathological fractures. The surgical intervention may be in the form of intralesional curettage [space then filled by bone graft or cement], intralesional excision [the preferred treatment option; similar to curettage but permits the use of different forms of adjuvants and reduce recurrence rate], or En bloc excision[7]. Other treatment lines are radiotherapy, selective arterial embolization, marginal or even wide resections ${ }^{[8-9]}$.

Adjuvant therapy is recommended to reduce the local recurrence rate and includes high-speed burr followed by alcohol/phenol solutions, liquid nitrogen, argon beam coagulation, or bone cement. Bone grafts are used to fill the hole after complete curettage of the ABC cavity, and bone cement is preferred in areas close to articular surfaces[6].

The use of cryotherapy dates back to the middle of the seventeenth century [originally for dermatological uses]. Its use was then extended to fields of neurosurgery, gynecology, and eventually orthopedic surgery. The first use in orthopedics was carried out by Marcove and Miller ${ }^{[10]}$ to treat metastatic bone tumors, where liquid nitrogen was directly poured to fill the tumor cavity many times. It leads to ice crystals formation with subsequent osmotic instabilities and bone necrosis[11].

The rationale for the current approach lies on the ability of cryosurgery to achieve good local control of aggressive bone tumors [either benign or malignant]; and all eligible patients treated by the same technique, and followed up for a long period [at least for two years; 24 to 72 months]

Previously, we represented 16 cases of $A B C$ in the proximal femur treated by the same proposed approach, with favorable results[12]. Here we extended this experience and reviewed another 25 patients treated in our and other institutions [Ain Shams and Al-Azhar Universities, Egypt].

\section{AIM OF THE WORK}

In the current study, we updated our experience with a unique intervention to manage $A B C$ [Extended curettage and cryosurgery with reconstruction by autogenous bone graft].

\section{PATIENTS AND METHODS}

Twenty-five patients with $A B C$ at different locations were treated in ten years [September 2009 to September 2019] at our institutions [Ain Shams and Al-Azhar Universities, Egypt].

$A B C$ 's diagnosis had been confirmed [evident] by radiological evaluation; thus, no need for preoperative biopsy. The staging was carried out using standard $\mathrm{x}$-ray, computed tomography [CT] and/ or magnetic resonance imaging [MRI] for all lesions. The diagnosis was further confirmed by histopathology of curetted tissues. According to Wolf and Enneking[13], the lesions had been staging.

The operative technique was defined into three separate stages [tumor excision, cryotherapy, and reconstruction].

First stage: [the stage of tumor excision]: The involved bone had been exposed. Then, a cortical window [Figure 1] had been created. The 
window size was larger than the longest dimension of the $A B C$ to expose the entire tumor. To decrease the stress riser effect, the cortical window was an elliptical one with its axis parallel to the bone's long axis. The hand curette had been used to remove all gross tumor [Figure 2]. The inner shell of the tumor cavity [reactive shell] had been removed by high-speed burr drilling [Resection curettage] [Figure 3 and 4].

Second stage [the stage of cryosurgery [liquid nitrogen application]: Before applying liquid nitrogen, bone holes had been identified and sealed by gel foam. In addition, the surrounding tissues [e.g., skin, soft tissues, and neurovascular structures had been

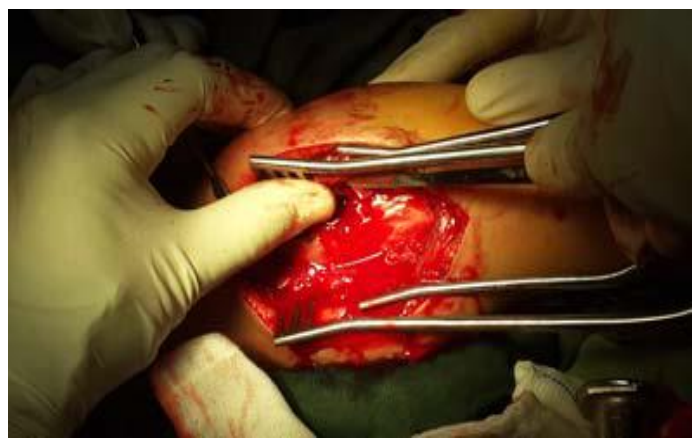

Figure [1]: The blood fill the tumor cavity after creation of cortical window

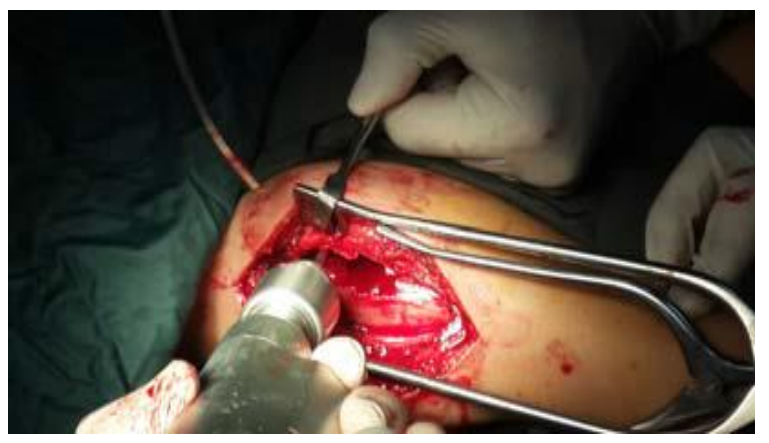

Figure [3]: Using a burr to extended curettage

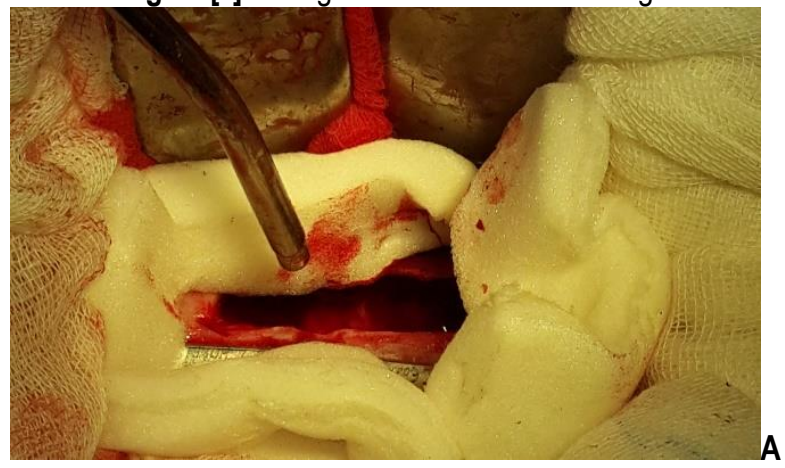

shielded by gel foam and gauze soaked with saline to protect them against extravasations of liquid nitrogen. Skin flaps are then retracted to protect them from any possible liquid nitrogen spillage. The direct pour technique had been applied as described by Marcove et al. for all the cases [Figure 5]. Warm normal saline had been used to irrigate the surrounding soft tissues to prevent thermal injury. Two cryotherapy cycles had been performed [freeze and thaw cycles], each lasting 1-2 minutes, and then a spontaneous thaw had been permitted to occur [lasts $3-5$ minutes]. Then, the cavity had been irrigated with normal saline to assure complete hemostasis.

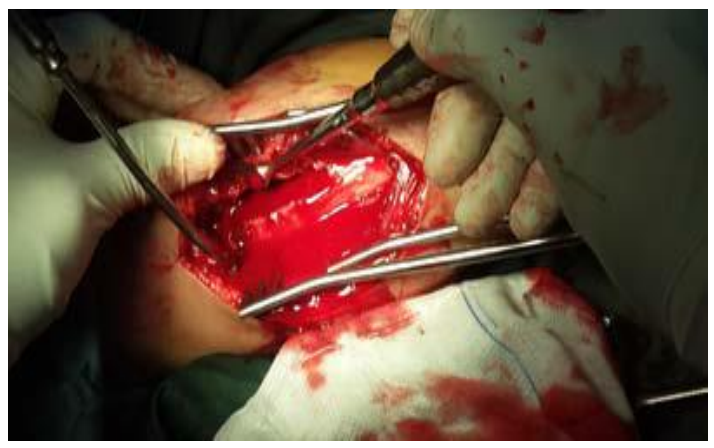

Figure [2]: Using standard curette to complete curettage of the cavity

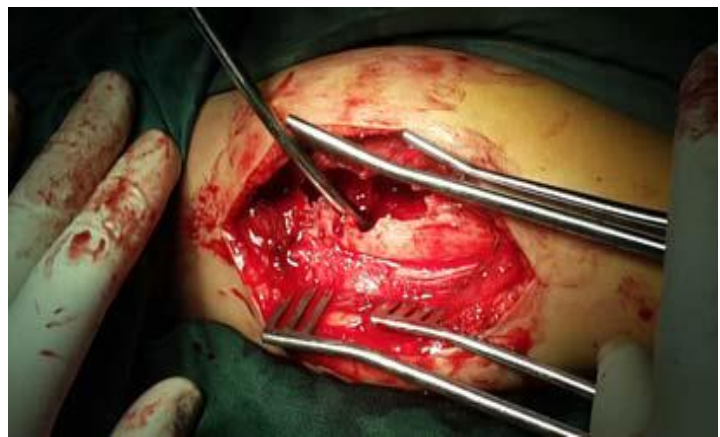

Figure [4]: The clean cavity after curettage

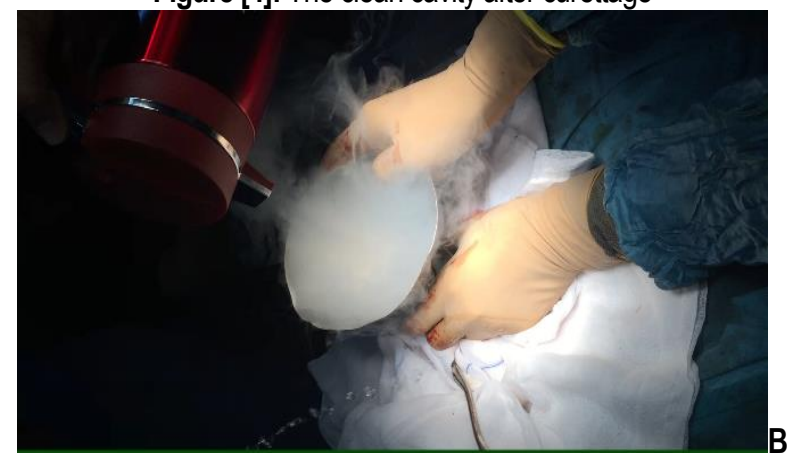

Figure [5]: Cryoablation [Applications of liquid nitrogen] 
Third stage [The stage of reconstruction and application of the graft]: After complete curettage and cryotherapy, the bone defect was reconstructed by harvesting a bone graft. In some patients, an autogenous fibular and strut bone graft had been used to add structural support [Figure 6]. Besides, internal plate fixation [Figure 7] had been applied at the proximal femur. A protective brace with or without cast had been used till graft incorporation and cyst ossification for 3 patients [Figures 8]. The follow up had been performed by clinical evaluation and radiological investigations at monthly intervals [for the first six months], then every two months for two years, and if continued, it carried every six months. The early follow-up visits had been scheduled to detect any local recurrence.

\section{Outcome}

Postoperatively, the patient had been evaluated by radiographic and functional evaluation. The radiographic evaluation had been achieved by the system developed by Heiple et al. [14], while functional evaluation had competed as described by Enneking et al.[15].
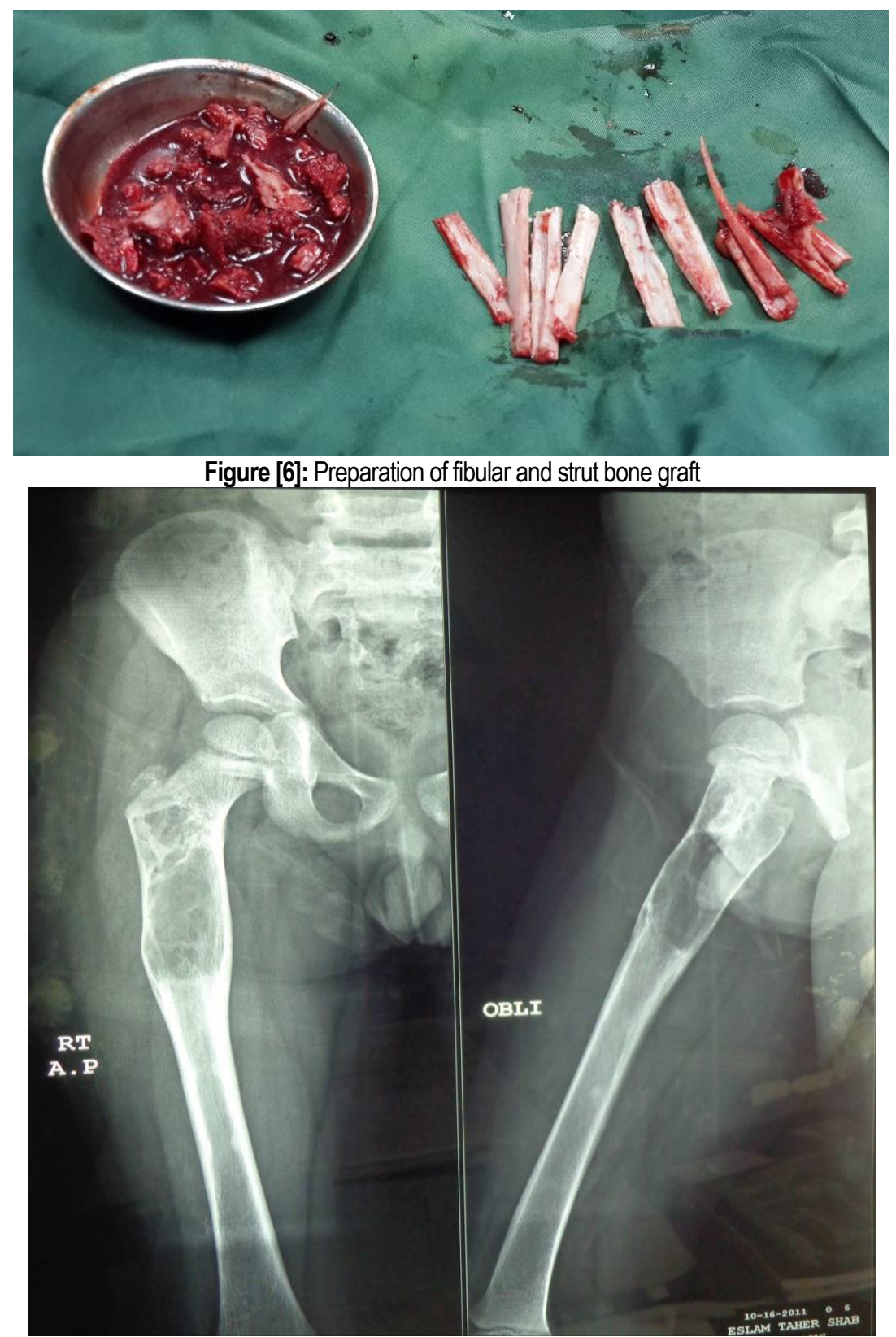

Figure [7]: Preoperative x-ray femur [10 years old child], anteroposterior and lateral showeing the ABC of the upper end. 

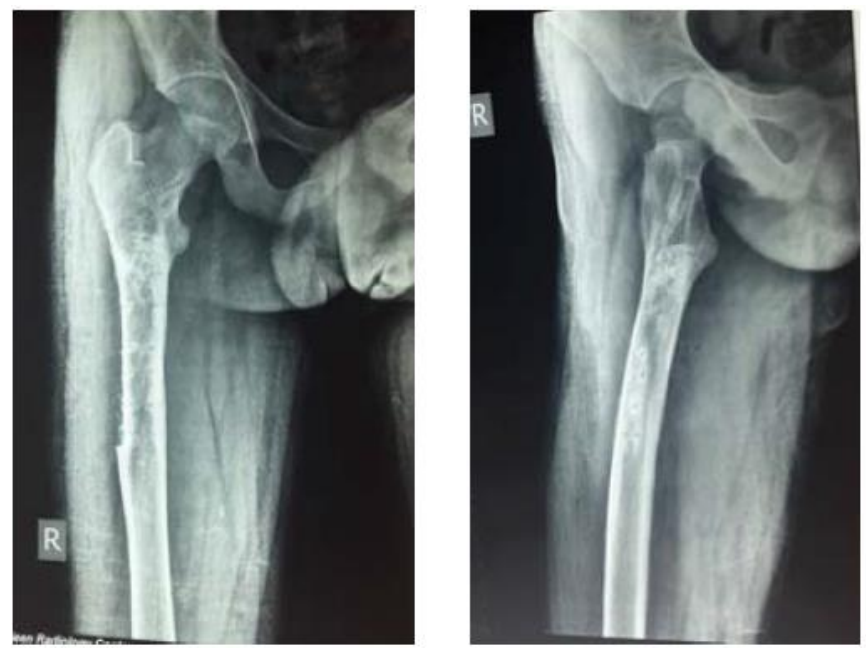

Figure [8]: X-rays anteroposterior and lateral views, 36 months post-operative with complete graft incorporation and bone remodeling after removal of plate and screws

\section{RESULTS}

Patient characteristics presented in [Table 1], males were 9 patients [36.0\%], while females were $16[64.0 \%]$; the average patient age was $14.64 \pm 5.64$ years [range 6-34 years]. All patients presented with pain and swelling, previous surgery reported in two patients [8.0\%], while none received preoperative radiotherapy or chemotherapy.

The $A B C$ had been presented in femur among 12 patients [six in proximal and six in distal femur]; other six were in the proximal tibia, four in the proximal humerus, two in the distal radius, and one in proximal ulna; 13 were on the right side and 12 on the left side [Table 2]. The graft had been obtained from the iliac crest for all patients. It was Corticocancellous among 17 patients [68.0\%], Corticocancellous with fibular strut graft among three patients, cancellous among two patients [8.0\%], cancellous with fibular strut graft among three patients [12.0\%]. The $A B C$ grade was grade 2 [active benign] among 20 patients [80.0\%] and grade 3 [aggressive benign] among 5 patients [20.0\%] [Table3]. The outcome presented in[ Table 4] and was as the following:
Radiological outcome: Union of the graft and healing of the $A B C$ had been achieved in all patients. However, partial graft resorption had been reported in two patients with cyst recurrence. Graft union and cyst healing were achieved at an average of $6.52 \pm 2.27$ months [4-14 months].

Functional outcome: At the end of the follow-up duration [mean duration $44.52 \pm 16.81$ months; range 24- 72 months], all patients were alive and completely free from the disease. The functional score [standard system of the musculoskeletal tumor society], at the final follow-up, ranges from $70 \%$ to $94 \%$, with an average of $85.12 \pm 7.32 \%$.

Complications: Graft resorption and tumor recurrence had been reported in two patients at the proximal femur with growth plate affection by a picture like Perth's disease and were managed by re-grafting after extended curettage, healing, and remodeling occurred within 6 months later on. Another two patients developed superficial post-operative wound infection, treated conservatively [daily dressing and antibiotics], and completely resolved within days.

Table [1]: Characteristics of studied patients

\begin{tabular}{|l|l|c|}
\hline \multicolumn{2}{|c|}{ Variables } & Statistics \\
\hline Sex [n,\%] & Male/ Female & $9[36.0 \%] / 16[64.0 \%]$ \\
\hline Age [years] & Mean \pm SD [min.-max.] & $14.64 \pm 5.64[6-34]$ \\
\hline Compliant [n,\%] & Pain / Swelling & $25[100.0 \%] / 25[100.0 \%]$ \\
\hline Previous surgery [n, \%] & Yes/ No & $2[8.0 \%] / 23[92.0 \%]$ \\
\hline Preoperative radio and/or Chemotherapy [n, \%] & Yes/No & $0[0.0 \%] / 25[100.0 \%]$ \\
\hline
\end{tabular}


Table [2]: Location and side of $A B C$ among studied patients

\begin{tabular}{|c|l|c|c|}
\hline \multicolumn{2}{|c|}{} & $\mathbf{n}$ & $\%$ \\
\hline \multirow{4}{*}{ Site } & Proximal Femur & 6 & 24.0 \\
\cline { 2 - 4 } & Proximal Tibia & 6 & 24.0 \\
\cline { 2 - 4 } & Distal Femur & 6 & 24.0 \\
\cline { 2 - 4 } & Proximal humerus & 4 & 16.0 \\
\cline { 2 - 4 } & Distal radius & 2 & 8.0 \\
\cline { 2 - 4 } & Proximal Ulna & 1 & 4.0 \\
\hline \multirow{7}{*}{ Side } & Right & 13 & 52.0 \\
\cline { 2 - 4 } & Left & 12 & 48.0 \\
\hline
\end{tabular}

Table [3]: Type of graft and grade of $A B C$ among studied patients

\begin{tabular}{|c|c|c|c|}
\hline & & $\mathbf{n}$ & $\%$ \\
\hline \multirow{4}{*}{$\begin{array}{l}\text { Type of } \\
\text { the graft }\end{array}$} & Corticocancellous iliac crest & 17 & 68.0 \\
\hline & Corticocancellous iliac crest \& Fibular strut graft & 3 & 12.0 \\
\hline & Cancellous iliac crest & 2 & 8.0 \\
\hline & Cancellous iliac crest\& fibular strut graft & 3 & 12.0 \\
\hline \multirow[t]{2}{*}{ Enneking grading } & Grade 2 [Active benign] & 20 & 80.0 \\
\hline & Grade 3 [Aggressive benign] & 5 & 20.0 \\
\hline
\end{tabular}

Table [4]: Outcome among studied patients

\begin{tabular}{|l|c|c|}
\hline & n. & $\%$ \\
\hline Recurrence and re-grafting & 2 & 8.0 \\
\hline Superficial infection & 2 & 8.0 \\
\hline Postoperative radiotherapy & \multicolumn{2}{|c|}{0} \\
\hline Postoperative chemotherapy & 0 & 0.0 \\
\hline Follow up duration [months] & \multicolumn{2}{|c|}{$44.52 \pm 16.81[24-72]$} \\
\hline Time to graft union and cyst healing [months] & \multicolumn{2}{|c|}{$6.52 \pm 2.27[4-14]$} \\
\hline Functional score \% & \multicolumn{2}{|c|}{$85.12 \pm 7.32$ [70-94] } \\
\hline
\end{tabular}

\section{DISCUSSION}

$A B C$ is a locally aggressive lesion that mandates surgical treatment. However, there is no consensus on a primary treatment option, and intralesional curettage with or without bone graft is the predominant therapy but had a higher risk of recurrence [about $20.0 \%$ or more] ${ }^{[1]}$.

Previously, we introduced cryotherapy to curettage with graft reconstruction for $A B C$ of the femur with marked reduction of recurrence rate $[6.25 \%]^{[12]}$.

In the current work, 25 patients with $A B C$ had been treated by extended curettage, cryotherapy, and bone graft with or without internal fixation. At the end of follow-up, all patients were alive and free from any local or systemic recurrence signs, with good functional outcome. Overall the outcome is satisfactory with a recurrence rate of $8.0 \%$ [which needed further intervention] and a postoperative infection rate of $8.0 \%$, which responded to conservative therapy.
The use of liquid nitrogen in the field of orthopedics is not new, and it had been used to treat stages 2 and 3 of low-grade malignant skeletal tumors. The application of cryotherapy serves to avoid extensive destruction of tissues and at the same time get rid of tumor cells ${ }^{[16-19]}$. It is a type of tissue ablation that induce coagulative necrosis. Cell death is thought to be due to crystallization of water molecules, interruption of local microcirculation [osmotic and electrolyte disturbances, denaturation of lipid-protein structures and vascular stasis] of targeted zone, and induction of apoptosis at the periphery[1]. Compared to local resection, cryoablation preserves the bone's supportive function with reconstructive surgery limitation[12]. Besides, compared to chemical ablation agents, cryosurgery leads to bony cell necrosis while preserving the inorganic osseous framework. Thus, it permits regeneration by sequential necrosis, osteogenesis, and bone remolding. Also, ice formation around cryoprobes permits precise treatment planning due to the prediction of ice size and shape ${ }^{[20]}$. 
Meller et al.,[21] presented their clinical experience with 440 cryosurgical procedures for 405 patients with different bone tumors and follow up period up to 18 years [3-18 years] and reported that cryotherapy permits bone conservation and is superior to resection surgery. They concluded that cryosurgery is a safe, effective, and reliable intervention for the conservation of limb, bone, joint, and epiphysis sparing surgery in specific types of bone tumors and for different ages. They defined specific criteria [based on their clinical experience] to define cryosurgery's ideal situation. These criteria are young adults, long bone, benignaggressive or low-grade bone tumor, good cavity, absence of soft tissue component, and at least \pm $1 \mathrm{~cm}$ of subchondral bone must be left near the joint surface after curettage. However, they challenged the open direct pour technique of liquid nitrogen application [difficulty in applications, hazards to nearby structures, difficulty in accurately controlling freezing parameters, and gravity dependence]. But, all these drawbacks are controllable in the current study.

Gibbs et al.[22] reported that adjuvant use aims to eradicate the microscopic disease with preservation of joints by intralesional curettage and use of adjuvants for benign bone lesions. Nogueira Drumond[23] confirmed this role and reported that the wide excision was associated with lower recurrence but had a worse functional outcome. Bickels et al. [17] selected liquid nitrogen cryosurgery as a curative treatment option for benign and low-grade bone tumors. They added that cryotherapy is useful for controlling and symptomatic relief of metastatic bone tumors and as effective as wide excision.

All previous studies, besides the current one, confirm the effectiveness and safety of cryotherapy when used as an adjuvant in the treatment of different bone tumors, including $A B C$.

We confirmed that the ideal reconstruction technique must have the following characters: biological affinity, hardly infected, had adequate strength, durable, and provide a permanent solution to the patient complaints [problems] without the need for revision surgery[12,24]. An allograft is an option to reconstruct the resulting defect after curettage of the ABC cavity[25]. However, it is associated with a higher rate of complications [e.g., graft fracture, resorption, nonunion, and infection]. Thus, limit its use[26].

The vascularized fibular bone graft is a more reasonable alternative for reconstructing the defect of $A B C$ after curettage. Lawal et al.[27] recommended using autologous free, cancellous bone with a non-visualized fibular graft to manage segmental bone loss after trauma or tumor excision.

Advantages of the autologous cancellous bone graft include easy incorporation, revascularization, and absence of immune-genicity[28,29],

Salama ${ }^{[30]}$ reported results for the use of nonvascularized fibular grafts augmented by cancellous bone for treatment of proximal femoral $A B C$ in eight patients. They noted full incorporation of the grafts at 12-16 months [mean 13 months] with good functional outcome irrespective of the development of coxa vara deformity in one patient.

When looking at other adjuvants than cryotherapy, phenol had been used and applied directly to the curetted surface to kill residual tumor and normal cells. However, the reported recurrence rate when used in $A B C$ is $12.0 \%$ to 20\%[1,31]. However, Capanna et al.[32] reported a low recurrence rate [7.0\%] when using phenol after curettage of benign bone lesions, which was significantly low when compared to the rate of recurrence without the use of phenol [41.0\%]. But, Kececi et al.[6] reported no benefit of phenol as an adjuvant on the recurrence rate. He used phenol after curettage of $A B C$ in 43 patients, compared to 19 patients with no adjuvant phenol, and reported a recurrence rate of $14 \%$ and $16 \%$ for phenol and non-phenol use, respectively.

Polymethylmethacrylate [PMMA] cement is used as an adjuvant to treat giant-cell bone tumors with good results and a lower recurrence rate [5.0\%]. Fahed et al.[33] reported successful treatment of painful $A B C$ by the application of PMMA. The proposed mechanism was the sclerotic effect of PMMA on the cyst wall, which is attributed to the chemical proprieties of bone cement or the local heating during bone cement polymerization. 
Interestingly, authors were not intended to treat $A B C$ but just stop bleeding during a biopsy. However, they noted the cyst regression with clinical and radiological improvement. Thus, they advocated the procedure for future $A B C$ treatment and defined it as a technically feasible and safe alternative.

Mankin et al. [34] reported a recurrence rate of $20 \%$, after intralesional excision, compared to $8 \%$ [two cases] in the current study after adding cryosurgery to the technique.

Schreuder et al.[29] treated 27 aneurysmal bone cysts by curettage and cryotherapy, with a longer follow-up duration [average 47 months [range 19 to 154 months] than the current work. Local recurrence in one patient [3.7\%], deep wound infection in two patients [7.4\%], and one patient [3.7\%] had a postoperative fracture. They compared their results to previous studies and concluded that curettage with adjuvant cryotherapy provided comparable results to marginal resection techniques with no need for bony reconstruction. They recommend the adjuvant use of cryotherapy for $A B C$ treatment to control the local tumor. Adding bone graft to the recommended protocol achieved consolidation of the lesion in all of their patients.

In conclusion, we recommend using curettage and adjuvant cryotherapy to treat $\mathrm{ABC}$. The addition of a bone graft allowed for consolidation in all cases with a short time for cyst healing.

Financial and Non-financial Relationships and Activities of Interest

None

\section{REFERENCES}

1. Grahneis F, Klein A, Baur-Melnyk A, Knösel T, Birkenmaier C, Jansson V, Dürr HR. Aneurysmal bone cyst: A review of 65 patients. J Bone Oncol. 2019 ; 18:100255. DOI: 10.1016/j.jbo.2019.100255.

2. Wang $T$, Jia Q, Gao X, Fan R, Wu Z, Guo W, Tang L, Qian M, Cai X, Zhao J, Xiao J. Secondary aneurysmal bone cyst of the spine: Clinicopathological features, surgical modalities and outcomes. Clin Neurol Neurosurg. 2020 Jan; 188:105595. DOI: 10.1016/j.clineuro.2019.105595.

3. Stevens KJ, Stevens JA. Aneurysmal Bone Cysts. 2020
Aug 15. In: StatPearls [Internet]. Treasure Island [FL]: StatPearls Publishing; 2020 Jan-. PMID: 31536260 .

4. Solooki S, Keikha Y, Vosoughi AR. Can ethanol be used as an adjuvant to extended curettage in order to reduce the recurrence rate of aneurysmal bone cyst? Rev Bras Ortop. 2016 Jul 20;52[3]:349-353. DOI: 10.1016/j.rboe.2016.04.007.

5. Basarir K, Piskin A, Güçlü B, Yildiz Y, Sağlik Y. Aneurysmal bone cyst recurrence in children: a review of 56 patients. J Pediatr Orthop. 2007 ;27 [8]: 938-43. DOI: 10.1097/bpo.0b013e31815a5fd3.

6. Kececi B, Kucuk L, Isayev A, Sabah D. Effect of adjuvant therapies on recurrence in aneurysmal bone cysts. Acta Orthop Traumatol Turc. 2014;48[5]:500-6. DOI: 10.3944/AOTT.2014.14.0020.

7. Park HY, Yang SK, Sheppard WL, Hegde V, Zoller SD, Nelson SD, Federman N, Bernthal NM. Current management of aneurysmal bone cysts. Curr Rev Musculoskelet Med. 2016 Dec;9[4]:435-444. DOI: 10.1007/s12178-016-9371-6.

8. Rossi G, Rimondi E, Bartalena T, Gerardi A, Alberghini M, Staals EL, Errani C, Bianchi G, Toscano A, Mercuri M, Vanel D. Selective arterial embolization of 36 aneurysmal bone cysts of the skeleton with N-2-butyl cyanoacrylate. Skeletal Radiol. 2010;39[2]:161-7. DOI: 10.1007/s00256-0090757-z.

9. Kumar P, Singh S, Phadke RV, Diwakar H, Agarawal T, Jain M, Datta NR. Role of radiotherapy in a recurrent aneurysmal bone cyst of the temporal bone: case report. Neurosurgery. 2006;58[3]: E584. DOI: 10.1227/01.NEU.0000197487.95078.6F.

10. Marcove RC, Miller TR. Treatment of primary and metastatic bone tumors by cryosurgery. JAMA. 1969 Mar 10; 207[10]:1890-4. PMID: 5304523.

11. Kollender Y, Meller I, Bickels J, Flusser G, Issakov J, Merimsky O, Marouani N, Nirkin A, Weinbroum AA. Role of adjuvant cryosurgery in intralesional treatment of sacral tumors. Cancer. 2003 Jun 1; 97[ 11]: 2830-8. DOI: $10.1002 / \mathrm{cncr} .11383$.

12. Abdel Rahman MA, El Masry AM, Azmy SI. Review of 16 cases of aneurysmal bone cyst in the proximal femur treated by extended curettage and cryosurgery with reconstruction using autogenous non vascularized fibula graft. J Orthop Surg [Hong Kong]. 2018 May-Aug; 26 [2]: 2309499018783905 [6 pages]. DOI: $10.1177 / 2309499018783905$.

13. Wolf RE, Enneking WF. The staging and surgery of musculoskeletal neoplasms. Orthop Clin North Am. 1996 Jul;27[3]:473-81. PMID: 8649730.

14. Heiple KG, Goldberg VM, Powell AE, Bos GD, Zika 
JM. Biology of cancellous bone grafts. Orthop Clin North Am. 1987 Apr; 18[2]:179-85. PMID: 3550570.

15. Enneking WF, Dunham W, Gebhardt MC, Malawar M, Pritchard DJ. A system for the functional evaluation of reconstructive procedures after surgical treatment of tumors of the musculoskeletal system. Clin Orthop Relat Res. 1993 Jan; [286]: 241-6. PMID: 8425352.

16. Marcove RC. A 17-year review of cryosurgery in the treatment of bone tumors. Clin Orthop Relat Res. 1982 Mar;[163]:231-4. PMID: 6950821.

17. Bickels J, Meller I, Shmookler BM, Malawer MM. The role and biology of cryosurgery in the treatment of bone tumors. A review. Acta Orthop Scand. 1999; 70 [3]: 308-15. DOI: 10.3109/17453679908997814.

18. Dabak N, Tomak Y, Piskin A, Gulman B, Ozcan H. Early results of a modified technique of cryosurgery. Int Orthop. 2003;27[4]:249-53. DOI: 10.1007/s00264003-0463-8.

19. Rose PS, Morris JM. Cryosurgery/cryoablation in musculoskeletal neoplasms: history and state of the art. Curr Rev Musculoskelet Med. 2015 Dec;8[4]:35360. DOI: $10.1007 /$ s12178-015-9307-6.

20. May L, Blatter J, Bize P, Tsoumakidou G, Denys A, Broome M. Percutaneous cryoablation of benign bony tumours of the mandible. $\mathrm{Br} \mathrm{J}$ Oral Maxillofac Surg. 2020;58[1]:75-78. DOI: 10.1016/j.bjoms.2019. 10.316 .

21. Meller I, Weinbroum A, Bickels J, Dadia S, Nirkin A, Merimsky O, Issakov J, Flusser G, Marouani N, Cohen N, Kollender Y. Fifteen years of bone tumor cryosurgery: a single-center experience of 440 procedures and long-term follow-up. Eur $\mathrm{J}$ Surg Oncol. 2008; 34[8]:921-7. DOI: 10.1016/j.ejso.2007. 11.001.

22. Gibbs CP, Lewis Vo, Peabody T. Beyond bone grafting: techniques in the surgical management of benign bone tumors. Instr Course Lect. 2005;54:497503. PMID: 15948474.

23. Nogueira Drumond JM. Benign bone tumors and tumorlike bone lesions: treatment update and new trends. Rev Bras Ortop. 2015 Dec 8; 44[5]:386-90. DOI: 10.1016/ S2255-4971[15]30267-6.

24. Nishida J, Shimamura T. Methods of reconstruction for bone defect after tumor excision: a review of alternatives. Med Sci Monit. 2008 Aug; 14[8]:RA10713. PMID: 18668007.

25. Malizos KN, Zalavras CG, Soucacos PN, Beris AE, Urbaniak JR. Free vascularized fibular grafts for reconstruction of skeletal defects. J Am Acad Orthop Surg. 2004 Sep-Oct; 12[5]:360-9. doi: 10.5435/ 00124635-200409000-00010.
26. Zaidenberg EE, Farias Cisneros E, Miller R, Zaidenberg CR. Metacarpal Aneurysmal Bone Cyst En Bloc Resection Reconstructed With Osteoarticular Allograft. J Hand Surg Am. 2019; 44[5]: 425.e1-425.e5. DOI: 10.1016/j.jhsa.2018.06.003.

27. Lawal YZ, Garba ES, Ogirima MO, Dahiru IL, Maitama MI, Abubakar K, Ejagwulu FS. Use of nonvascularized autologous fibula strut graft in the treatment of segmental bone loss. Ann Afr Med. 2011; 10[1]:25-8. DOI: 10.4103/ 1596-3519.76571.

28. Mascard E, Gomez-Brouchet A, Lambot K. Bone cysts: unicameral and aneurysmal bone cyst. Orthop Traumatol Surg Res. 2015 Feb; 101[1 Suppl]:S11927. DOI: 10.1016/j.otsr.2014.06.031.

29. Schreuder HW, Veth RP, Pruszczynski M, Lemmens JA, Koops HS, Molenaar WM. Aneurysmal bone cysts treated by curettage, cryotherapy and bone grafting. J Bone Joint Surg Br. 1997 Jan; 79[1]:20-5. DOI: 10.1302/0301-620x.79b1.7097.

30. Salama AM. Fibular graft for reconstruction of proximal femoral aneurysmal bone cysts. Egy Orthop J 2016, 51:143-146. DOI: 10.4103/1110-1148.203148

31. Lin WH, Lan TY, Chen CY, Wu K, Yang RS. Similar local control between phenol- and ethanol-treated giant cell tumors of bone. Clin Orthop Relat Res. 2011 Nov; 469[11]:3200-8. DOI: 10.1007/s11999011-1962-3.

32. Capanna R, Sudanese A, Baldini N, Campanacci M. Phenol as an adjuvant in the control of local recurrence of benign neoplasms of bone treated by curettage. Ital J Orthop Traumatol. 1985 Sep; 11 [3]: 381-8. PMID: 4086284.

33. Fahed R, Clarençon F, Riouallon G, Cormier E, Bonaccorsi R, Pascal-Mousselard H, Chiras J. Just a drop of cement: a case of cervical spine bone aneurysmal cyst successfully treated by percutaneous injection of a small amount of polymethyl-methacrylate cement. J Neurointerv Surg. 2016 Jan; 8 [1]:e4. DOI: 10.1136/ neurintsurg-2014011541.rep.

34. Mankin HJ, Hornicek FJ, Ortiz-Cruz E, Villafuerte J, Gebhardt MC. Aneurysmal bone cyst: a review of 150 patients. J Clin Oncol. 2005 Sep 20; 23[27]: 6756-62. DOI: 10.1200/JCO.2005.15.255. 


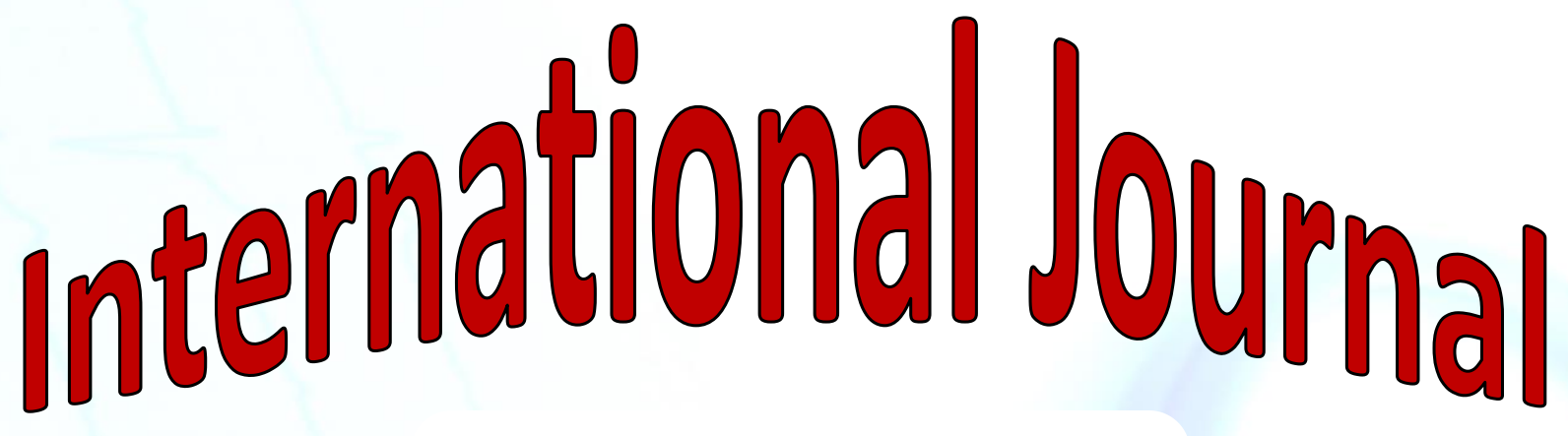

https://ijma.journals.ekb.eg/

Print ISSN: 2636-4174

Online ISSN: 2682-3780

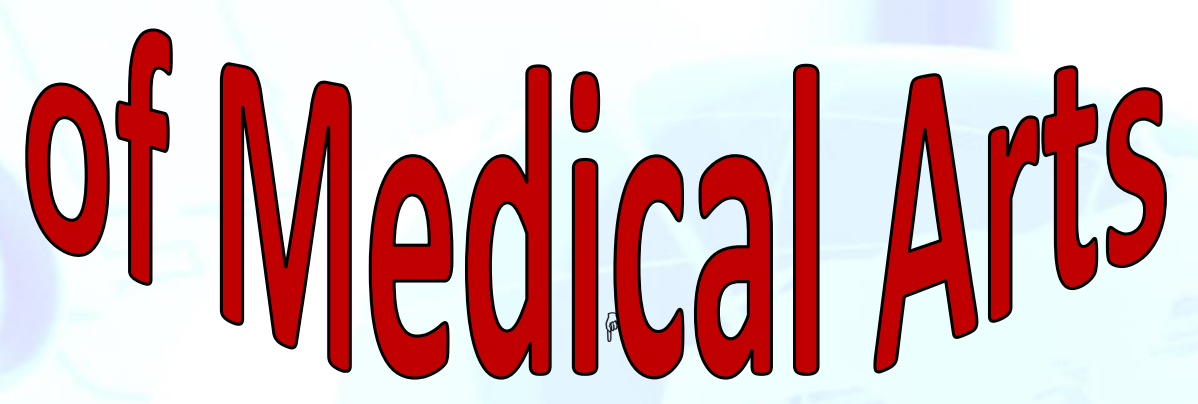

